\title{
Osteoarthritis of the knee in Nigerians
}

\author{
WALTON W EBONG \\ From the Orthopaedic Unit, College of Medicine, University. of Ibadan, Nigeria
}

SUMMARY Eighty-one patients with 116 osteoarthritic knees were seen by the author at thẹ University College Hospital (UCH), Ibadan in six years. Below the age of 50 the disease was significantly commoner among Nigerians than Caucasians; $39.5 \%$ of our patients were less than 50 years old, compared with $1 \cdot 1 \%$ of Caucasians. In contrast with the latter group, trauma wa结 apparently an insignificant predisposing factor of knee degeneration in our patients. In some cases osteoarthritis was associated with severe valgus deformity in rather young patients $s_{i+}^{+}$ suggesting a probable causal relationship. Multiple joint osteoarthritis was significantly les common in Nigerians than in Caucasians.

Key words: Africa-western, Nigeria.

Although osteoarthritis is a frequent and important cause of pain and disability worldwide, its pattern of joint involvement varies from place to place. ${ }^{1}$ For instance, primary osteoarthritis of the hip is common in Caucasians ${ }^{2}$ but it is very rare in black Africans $^{34}$ and in Hong Kong Chinese. ${ }^{5}$ Such differences in the prevalence of the disease have been attributed to genetic and environmental factors (in the form of occupational stresses and individual episodes of trauma). ${ }^{6}$

Information obtained from studies of the pattern of the disease in different continents could be important in planning for control and prevention and might contribute to a further understanding of the pathogenesis of the disease. ${ }^{6}$ Although adequate information exists on the pattern of the disease in the developed countries, ${ }^{26}$ there are very few studies from tropical Africa. ${ }^{4}$ Apart from the studies of the hip ${ }^{4}$ we were unable to find any previous reports on how the pattern of osteoarthritis of the major joints in this region compared with the pattern of the disease elsewhere.

Solomon ${ }^{3}$ stated that osteoarthritis of the knee was common in black South Africans, but he did not present any specific data.

This paper reviews 116 osteoarthritic knees in 81 patients seen by the author at UCH, Ibadan in a sixyear period.

\section{Patients and methods}

The case files and radiographs of 81 patients with

Accepted for publication 19 March 1985.

Correspondence to Dr W W Ebong. osteoarthritis of the knee seen by the author in the

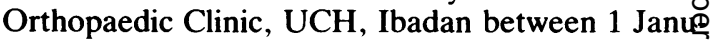
ary 1977 and 31 December 1982 were reviewed. Att the patients were Nigerian Negroes. In most çese the $x$-rays were not carried out in a weight-bear ng or stressed position as suggested by Ahlback. ${ }^{7}$ joints were graded for osteoarthritis on a scale of (normal) to 4 by the criteria of Kellgren an Lawrence ${ }^{8}$ : grade 1, doubtful osteoarthritis; grade 2 , minimum; grade 3 , moderate; grade 4 , severe osteoarthritis. Only grades 3 and 4 (moderate an $\overrightarrow{8}$ severe osteoarthritis) were considered in this study because of the difficulty in defining the lesse? degrees of osteoarthritis. Thus the presence of. osteophytes alone was not accepted as evidence of osteoarthritis of the knee; rather the radiographi demonstration of narrowing of the joint spact and/or subchondral sclerosis was a precondition fow inclusion in this series. ${ }^{9}$

\section{Results}

AGE AND SEX INCIDENCE

The age at onset of symptoms varied from 25 to $9 \$$ years, mean 52 years (Table 1). The mean for maless was 49.4 years (range $25-90$ ), that for females $52 . \$$ years (range $27-85)$. Thirty-two patients $(39.5 \% 9$ were under the age of 50 . Fifty-four of the 81 patients $(66.7 \%)$ were women, a sex ratio of $2:$ 욷

\section{DISTRIBUTION OF JOINT INVOLVEMENT}

In 35 patients $(43.2 \%)$ both knees were affectedo The right knee alone was involved in 30 cases and the left knee alone in 16. Narrowing of only one of 
Table 1 Clinical findings in Nigerians with gonarthrosis

\begin{tabular}{|c|c|c|c|}
\hline & $\begin{array}{l}\text { Males } \\
(n=27)\end{array}$ & $\begin{array}{l}\text { Females } \\
(n=54)\end{array}$ & $\begin{array}{l}\text { Total } \\
(n=81)\end{array}$ \\
\hline Mean age (range) years & $49.4(25-90)$ & $52 \cdot 3(27-85)$ & $52(25-90)$ \\
\hline Mean duration (range) of symptoms & $\begin{array}{l}3 \mathrm{yrs} 3.7 \mathrm{mos} \\
(2 \mathrm{wks}-12 \mathrm{yrs})\end{array}$ & $\begin{array}{l}3 \text { yrs } 1.4 \text { mos } \\
(2 \text { wks }-20 \text { yrs })\end{array}$ & $\begin{array}{l}3 \text { yrs } 2.5 \mathrm{mos} \\
(2 \mathrm{wks}-20 \mathrm{yrs})\end{array}$ \\
\hline Polyarticular features & & $4 / 54$ & $4 / 81$ \\
\hline Obese & $1 / 27$ & $14 / 54$ & $15 / 81$ \\
\hline \multicolumn{4}{|l|}{ Occupation: } \\
\hline Petty trading & 2 & 18 & 20 \\
\hline Domestic work & & 27 & 27 \\
\hline Subsistent farming & 9 & 5 & 14 \\
\hline Unskilled labourers & 8 & & 8 \\
\hline Teaching & 2 & 4 & 6 \\
\hline Skilled labourers + professionals & 6 & & 6 \\
\hline
\end{tabular}

the three articulations of the knee was observed in 103 of the 116 knees. Thus only 13 knees $(11 \cdot 2 \%)$ had combinations of more than one articulation with narrowing of the joint space.

I N J U R Y

A history of previous trauma or radiological evidence of an injury were present in three of the 27 males $(11 \cdot 1 \%)$ and in none of the females.

\section{O B E S I T Y}

Any person more than $10 \%$ above average weight was considered to be obese ${ }^{6}$ and by this definition $3.7 \%$ (1) of the males and $25.9 \%$ (14) of the females were overweight. One obese female had bilateral genu varum, and another had genu valgum.

\section{KNEE ANGULATION}

A varus knee was defined as one with tibiofemoral angle of $4^{\circ}$ of valgus or less, a neutral knee as from $5^{\circ}$ to $9^{\circ}$ of valgus, and a valgus knee as one with $10^{\circ}$ or greater of valgus. This division was based on the normal valgus of $7^{\circ}$ as reported by Steindler ${ }^{10} \pm 2^{\circ}$ latitude in the neutral group, even though it has not yet been shown that this standard is applicable to West Africans. By these criteria 16 patients $(19 \cdot 8 \%)$ presented with genu valgum (five bilateral and 11 unilateral), one patient had varovalgus deformity, and another had bilateral genu varum. Thus valgus and varus deformities occurred in 22 and three knees respectively. One patient had genu recurvatum.

\section{OTHER FEATURES}

Domestic work and petty trading were the predominant occupations for 45 females (Table 1).

Most (17) men were unskilled labourers or subsistent farmers. The mean duration of symptoms when first seen was 3 years 2.5 months (range two weeks to 20 years). Pain, the cardinal symptom, was present in all cases. Forty-one patients $(50 \cdot 6 \%)$ also complained of stiffness and difficulty with squatting. Twenty-six patients $(32 \cdot 1 \%)$ presented with knee swelling, and $19(23.5 \%)$ with limping and knee deformity. One patient had guinea worm arthritis and one, loose bodies in the knee.

Degenerative disease was also found in the lumbar spine of eight patients. None of the 81 patients was known to suffer from sickle cell disease, and few were severely crippled by the degenerative disease. Most patients improved sufficiently on conservative measures to require no surgery. Upper tibial osteotomy was performed on 10 knees and patellectomy on two others. Double osteotomy, arthrodesis, and removal of loose bodies were each carried out on one knee. The early results of upper tibial osteotomy appeared satisfactory in seven of the 10 knees with regard to retention of mobility, relief of pain, and achievement of stability. The other three patients each had delayed union, persistent instability, and pain. Stiffness of the knee and lack of adequate mobility occurred in the only patient who had upper tibial and supracondylar femoral osteotomies (double osteotomy) for osteoarthritis and severe valgus deformity.

\section{Discussion}

In contrast with the hip, ${ }^{4}$ the pattern of osteoarthritis of the knee in Nigerians was similar in many respects to the pattern in Caucasians, but some differences were noted. As in reports elsewhere females predominated in this series. However, the female preponderance was less marked in our series, perhaps because many of our patients were relatively young. ${ }^{7}$ It is known that the female to male ratio in this disease increases with age. ${ }^{7}$

Under 50 years of age osteoarthritis of the knee 
was more common in Nigerians than in Caucasians. About $40 \%$ ( 32 out of 81 ) of our patients and 1\% (3 out of 281) of Swedish patients ${ }^{7}$ with degenerative disease of the knee were less than 50 years old. The reason for this younger age of our patients is unknown, and no obvious predisposing cause was found in most of the cases. Hernborg and Nilsson ${ }^{11}$ suggested that the onset of symptoms at an early age was unfavourable with regard to the development of pain.

Trauma was apparently a less significant factor in osteoarthritis of the knee in Ibadan patients than in Caucasians. In Caucasian males trauma has been found to be associated with osteoarthritis of the knee in about half of the cases. ${ }^{6}$ It is possible that some of our patients had forgotten previous injuries; however, it may be that differences in occupational hazards partly accounted for this difference in the prevalence of knee injuries. For instance, most of the men studied by Kellgren and Lawrence ${ }^{6}$ were coal miners, in whom knee injury is quite common.

The role of obesity as an aetiological factor in osteoarthritis remains unresolved. Large population studies of patients with osteoarthritis have shown an increased incidence of degenerative arthritis of the knee in obese individuals. ${ }^{2612}$ Other investigators, ${ }^{13-15}$ however, have been unable to find an increase in body weight among women with degenerative changes of the knee as compared with women with normal knees. About a quarter of the females in our series were overweight, but the question of whether obesity relates to the aetiology of osteoarthritis of the knee cannot be resolved from our data.

It is not clear whether osteoarthritis develops more frequently in patients with valgus or varus deformity. ${ }^{16}$ Knee deformities are very common in Nigerian children, and some adults are seen with neglected, gross deformities. It is not possible to say categorically from the present study whether the observed valgus deformity was the cause or result of the knee degeneration. However, we were struck by some rather young adults with severe genu valgum who presented with marked osteoarthritic knees. It may be that although minor degrees of genu valgum are not necessarily related to osteoarthritis, severe degrees of the deformity are related, just as the more severe degrees of hallux valgus have been found to predispose to osteoarthritis of the metatarsophalangeal joints. ${ }^{6}$ Both valgus and varus defor- mities are known to be associated with a greatex

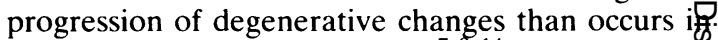
knees with neutral angulation. ${ }^{7914}$ However, the progression of degeneration for a given patien cannot be predicted with sufficient certainty to warrant prophylactic reconstruction. ${ }^{14}$

Polyarticular osteoarthritis affecting three more joints ${ }^{17}$ was uncommon in this series and occurred in only four patients $(4.9 \%)$. In contrast the incidence of multiple osteoarthritis in an English population was $24 \%$. ${ }^{6}$ The reason for this lowe? incidence of polyarticular osteoarthritis in African Negroes is not known, but the occurrence has beepp reported previously. ${ }^{17}$

\section{References}

1 Radin E L, Paul I L, Rose R M. Role of mechanical factors pathogenesis of primary osteoarthritis. Lancet 1972; i: 519-2Х

2 Kellgren $\mathrm{J} \mathrm{H}$. Osteoarthrosis in patients and populations. Med J 1961; ii: 1-6.

3 Solomon L. Pathogenesis of osteoarthritis [letter]. Lancet $197 \overrightarrow{2}$ i: 1072 .

4 Ebong W W. Lawson E A L. Pattern of osteoarthritis of the hi़ in Nigerians. East Afr Med J 1978; 55: 81-4.

5 Hoaglund F T, Yau A C M C. Wong W L. Osteoarthritis of the hip and other joints in Southern Chinese in Hong Kong. $J$ bove Joint Surg 1973; 55A: 545-57.

6 Kellgren J H. Lawrence J S. Osteoarthrosis and disk degereration in an urban population. Ann Rheum Dis 1958; 17: 38.

7 Ahlback S. Osteoarthrosis of the knee. A radiographic smd Acta Radiol [Suppl] (Stockh) 1968: 277.

8 Kellgren J H. Lawrence J S. Radiological assessment osteoarthrosis. Ann Rheum Dis 1957; 16: 494-502.

9 Danielson L. Hernborg J. Morbidity and mortality of osteo thritis of the knee (gonarthrosis) in Malmo, Sweden. C Orthop 1970; 69: 224-6.

10 Steindler A. Kinesiology of the human body under normal a pathological conditions. Springfield, Illinois: Thomas, 195 331.

11 Hernborg J S, Nilsson B O. The natural course of untreated osteoarthritis of the knee. Clin Orthop 1977; 123: 130-7.

12 Lawrence J S, Bremner J M. Bier F. Osteoarthrosis. Prevalence in the population and relationship between symptoms and $x$-ray changes. Ann Rheum Dis 1966; 25: 1-24.

13 Danielson L, Hernbory J. Clinical and roentgenologic study knee joints with osteophytes. Clin Orthop 1970; 69: 302-18.

14 Miller R, Kettlekamp D B, Laubenthal K N, Karagiorges $\bar{\theta}$ Smidt G L. Quantitative correlations in degenerative arthrims of the knee. J Bone Joint Surg 1973; 55A: 956-62.

15 Goldin R H, Mc-Adam L, Louie J S, Gold J, Bluestone $\overline{\mathbf{R}}$ Clinical and radiological survey of the incidence of osteoarthro sis among obese patients. Ann Rheum Dis 1976; 35: 349-50

16 Heberden Society Clinical Meeting. Osteoarthrosis of the knẹ Ann Rheum Dis 1970; 29: 190.

17 Solomon L, Beighton P, Lawrence J S. Osteoarthrosis in a ruf South African Negro population. Ann Rheum Dis 1976; 3: 274-8. 